\title{
Acute-on-chronic subdural hematoma
}

\author{
Brian T. Kloss • Richard E. Lagace
}

Received: 19 April 2010 / Accepted: 18 August 2010/Published online: 2 November 2010

(C) The Author(s) 2010. This article is published with open access at Springerlink.com

A 38-year-old male complains of a right-sided retro-orbitaltemporal headache of 2-day duration. It is described as intermittent and pressure-like, and is preceded by bouts of left arm numbness. He denies diplopia, visual changes, nausea, vomiting, or alterations in his consciousness. No acute trauma is reported, but he gives a history of airline

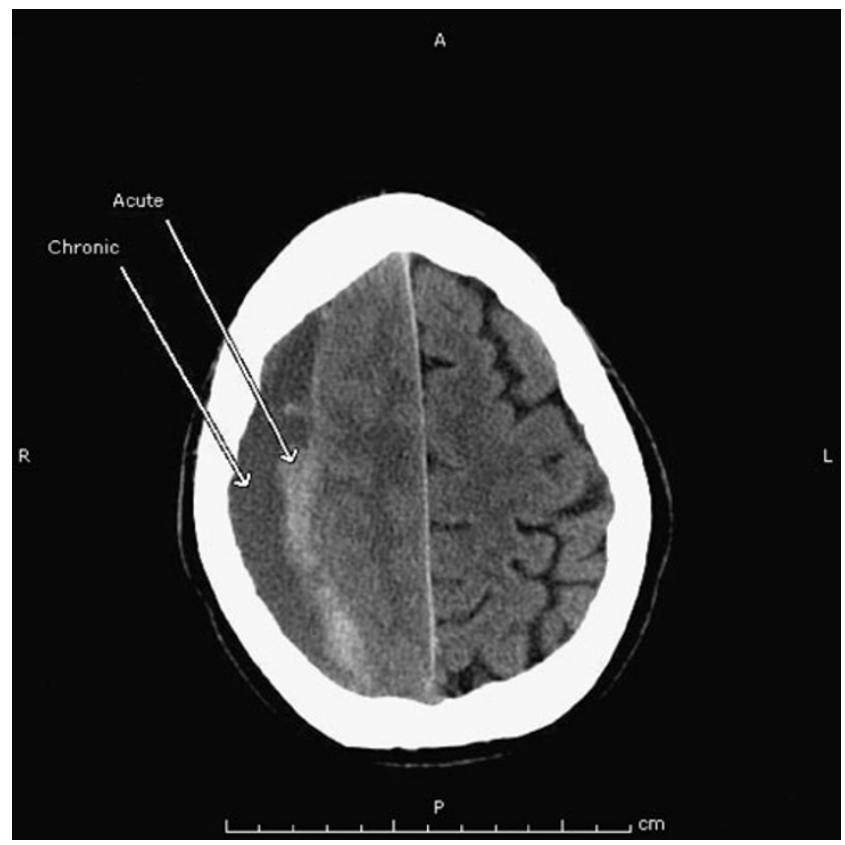

Fig. 1 Acute bleed is hyperdense and chronic is hypodense

\section{B. T. Kloss $(\bowtie) \cdot$ R. E. Lagace}

Department of Emergency Medicine,

SUNY Upstate Medical University,

550 East Genesee Street Syracuse,

New York 13202, USA

e-mail: klossb@upstate.edu travel within the past $24 \mathrm{~h}$. His parents are present at the bedside and volunteer that the patient and his wife were involved in a motorcycle crash 3 months ago in which his wife was killed.

The patient is alert and oriented with normal vital signs and a normal physical exam. A CT of the head without contrast is performed and reveals an acute-on-chronic subdural hematoma with a 1.6-cm midline shift (Figs 1, 2 and 3). Neurosurgery is performed emergently.

Subdural hematoma (SDH) is a collection of blood between the dura and arachnoid membranes not restricted by cranial sutures. They do not cross the midline because of the menigeal reflections and are classified as: acute, chronic, or as in this case, acute-on-chronic. An acute $\mathrm{SDH}$ is hyperdense (white) on CT, whereas a sub-acute

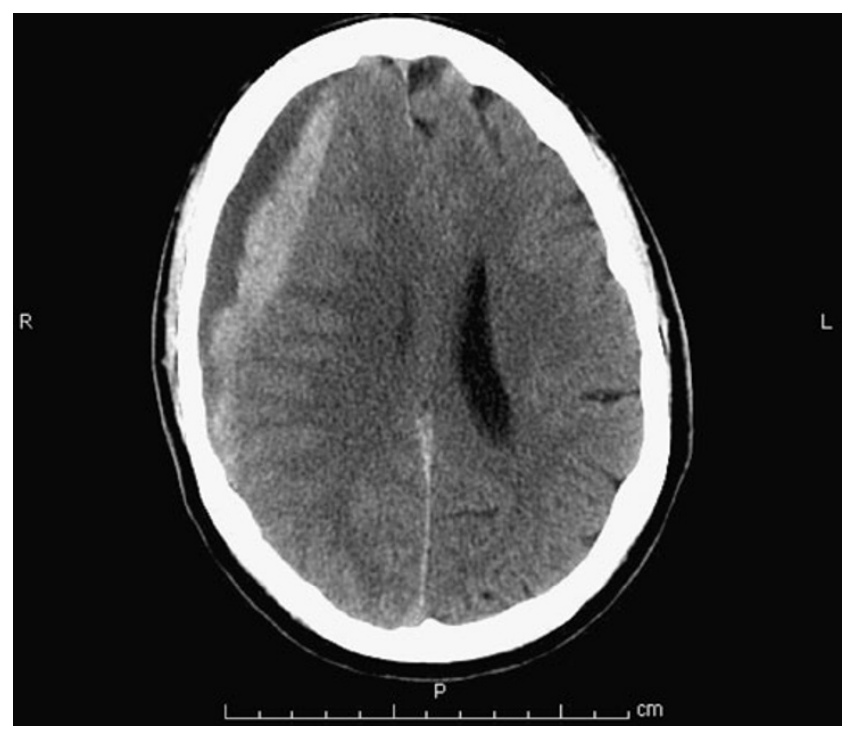

Fig. 2 CT head showing acute-on-chronic SDH 


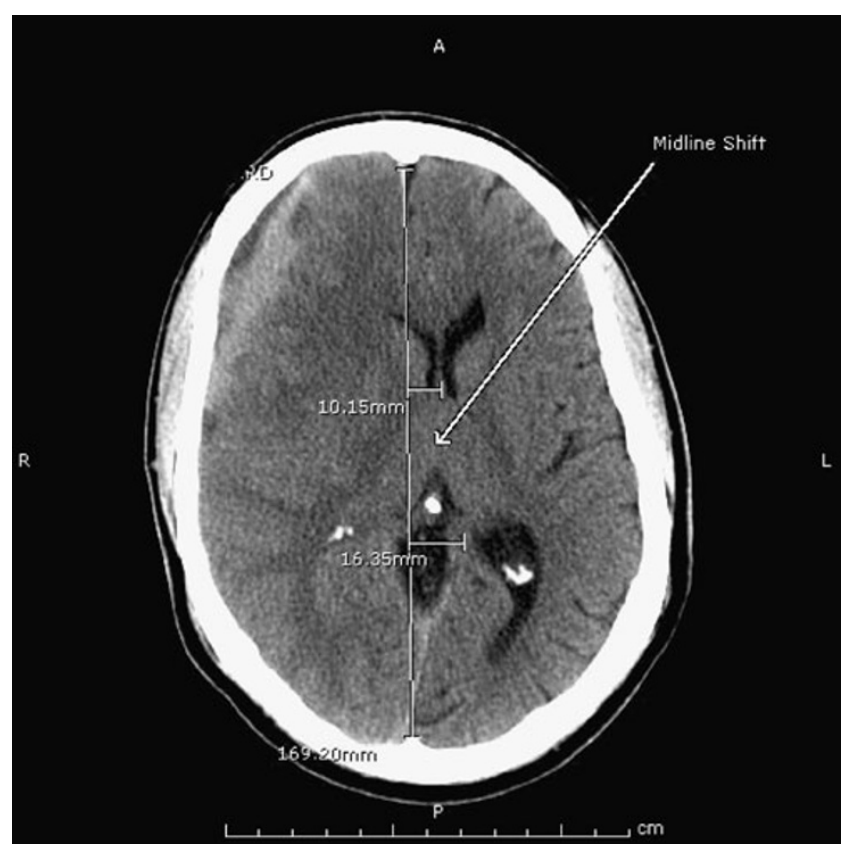

Fig. 3 CT head showing a midline shift to the left
SDH will appear isodense (grey) and hypodense (black) when chronic. A chronic SDH is a collection of blood breakdown products that has been present for at least 3 weeks and can become acute-on-chronic if small hemorrhages in the collection occur. Common signs and symptoms of a chronic SDH include: headache (90\%), hemiparesis $(58 \%)$, confusion (56\%), and a decreased level of consciousness (40\%) [1].

Open Access This article is distributed under the terms of the Creative Commons Attribution Noncommercial License which permits any noncommercial use, distribution, and reproduction in any medium, provided the original author(s) and source are credited.

\section{References}

1. Meagher, R. Subdural Hematoma. The EMedicine Clinical Knowledge Database [online] Nov 2, 2006 available at: http://www. emedicine.com/neuro/TOPIC575.HTM 